\title{
Hazards Data Distribution System (HDDS)
}

When emergencies happen, first responders and disaster response teams often need rapid access to aerial photography and satellite imagery that is acquired before and after the event. The U.S. Geological Survey (USGS) Hazards Data Distribution System (HDDS) provides quick and easy access to pre- and post-event imagery and geospatial datasets that support emergency response and recovery operations. The HDDS provides a single, consolidated point-of-entry and distribution system for USGS-hosted remotely sensed imagery and other geospatial datasets related to an event response. The data delivery services are provided through an interactive map-based interface that allows emergency response personnel to rapidly select and download pre-event ("baseline") and post-event emergency response imagery.

\section{Available Datasets}

- Post-event aerial and (or) satellite imagery, including

- Moderate-resolution satellite imagery

- High-resolution commercial satellite imagery

- High-resolution aerial imagery

- Pre-event "baseline" imagery, such as

- Orthorectified aerial photography (by U.S. county)

- Moderate- or high-resolution satellite imagery

\section{Hazards Data Distribution System (HDDS) Features}

- Interactive, map-based graphical interface

- Immediate download access for available datasets

- Search by event, date, and (or) location

- Geographic search by place name, coordinates, or uploaded file (shapefile of KML)
- Browse image and footprint area overlay on a map background

- Enhanced browse visualization (such as browse comparison or browse opacity adjustment)

- Metadata export in multiple formats (KML, SHP, CSV, XML, and FGDC)

- XML-based Really Simple Syndication (RSS) feeds for newly added data

- Standing request service for automatic notification of new data availability

- User-specified Web Mapping Service (WMS) creation based on image selections

- User registration service and login access for restricted datasets

- Bulk data download capability via downloadable client

- User feedback and Help documentation

w.

Hurricane Isaac leaves flooded homes in his wake near the community of Braithwaite, Louisiana, September 4, 2012. Photograph by Brady Couvillion, U.S. Geological Survey. 


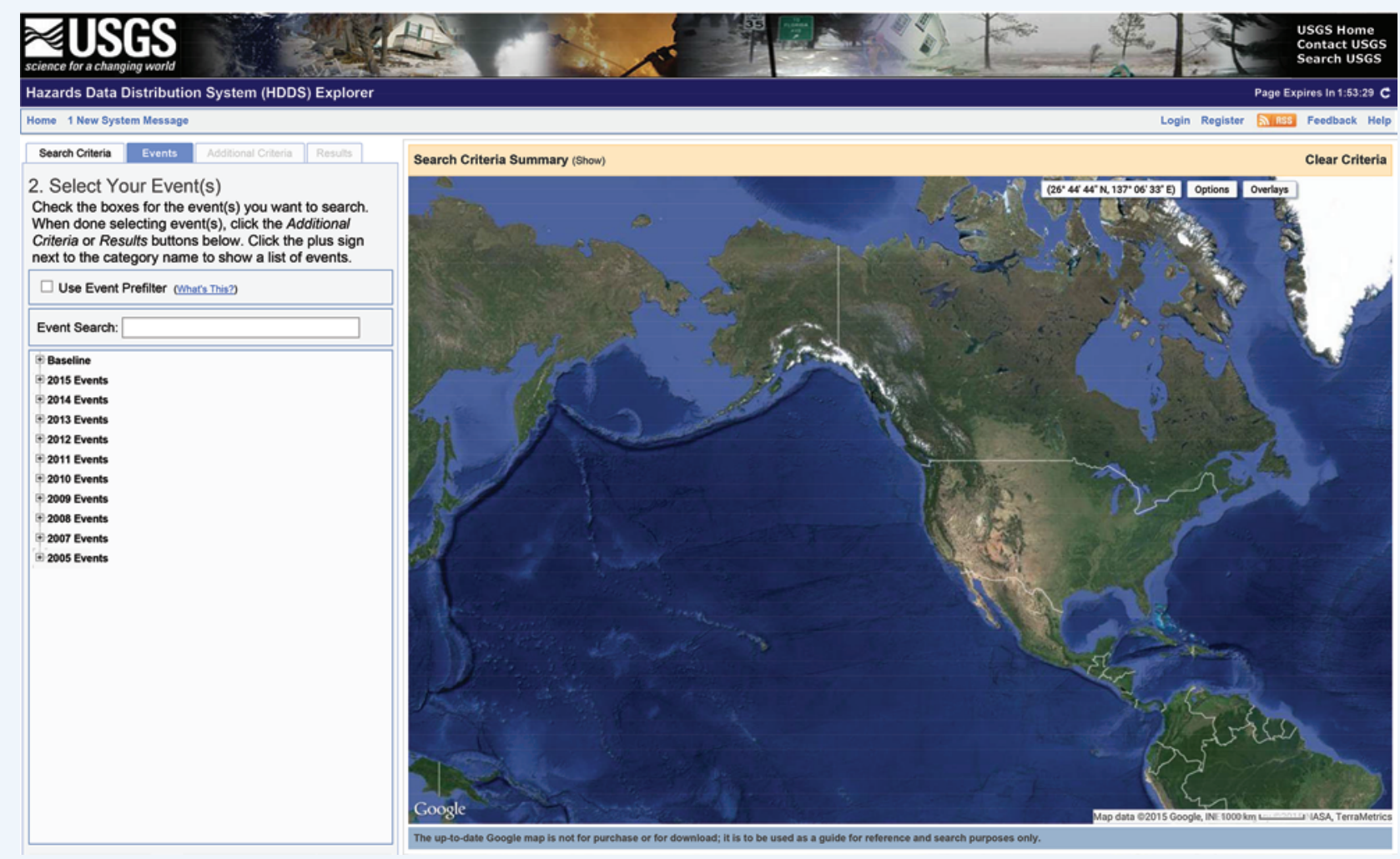

Figure 1. Screen capture of the USGS Hazards Data Distribution System (HDDS) home page.

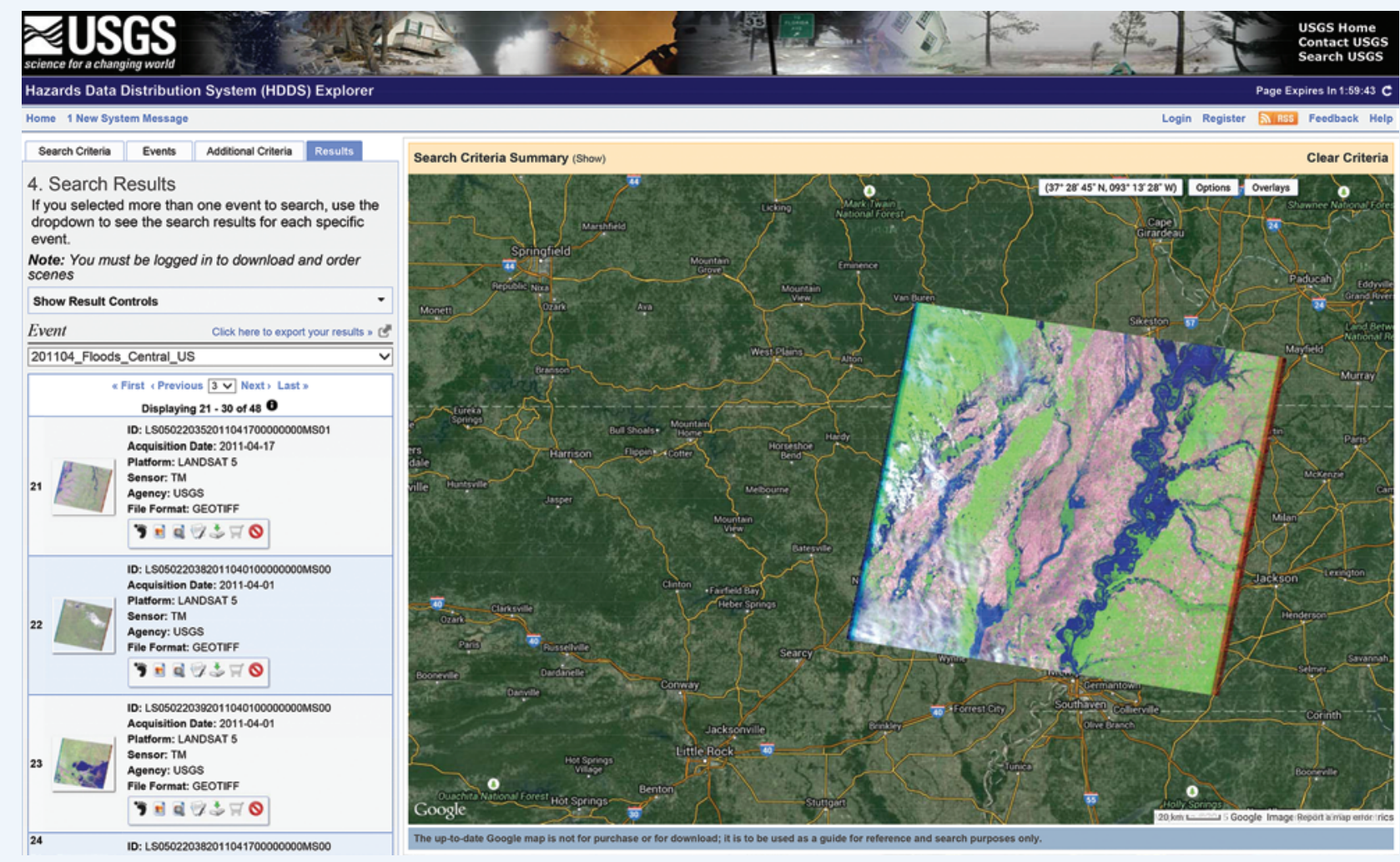

Figure 2. Screen example of the Hazards Data Distribution System (HDDS) image search results for 2011 flooding along the Mississippi River. Example browse image is a Landsat Thematic Mapper (TM) scene acquired on May 10, 2011.

\section{For more information}

Hazards Data Distribution System (HDDS): http://hddsexplorer.usgs.gov/ USGS Emergency Operations Portal: http://eoportal.usgs.gov 